\title{
Mycosis fungoides mimicking neurofibromatosus and aspergillosis: reports of two unusual presentation and literature review
}

\begin{abstract}
Background: Mycosis fungoides, a primary cutaneous T-cell lymphoma is a rare malignant skin neoplasm. Its diagnosis is often missed as it can masquerades as benign skin lesions. The aetiology and risk factors of the disease are poorly characterized and not well defined. In Nigeria, the disease seems to be rare or under reported, as there is dearth of studies on it. Mycosis fungoides resembles many skin lesions such as nodular acne and epidermoid cyst, particularly during early in its clinical course, creating diagnostic challenges, especially in developing countries due to lack of expertise and facilities. It diagnosis is established through tissue biopsy, histological diagnosis with Hematoxylin and Eosin and immune histo chemistry.
\end{abstract}

Case Reports: We report two cases of mycosis fungoides found in our achieved (2003-2016). The first case is a 20 year old young lady that presented with a pair of painless nodular swelling on the left facial region. The other case involved a 60 year old female who presented with history of patchy pigmented skin lesions involving the left arm associated with itching.

Conclusion: Mycosis fungoides has a varied presentation; it is often overlooked as it present as indolent lesion. Histopathology of tissue specimen, an examination that requires skill and expertise is required for its diagnosis. High index of suspicious skin lesion by clinician is necessary for detecting cutaneous lesion.
Volume 3 Issue 2 - 2018

\author{
Bukar Abba Zarami,' Ballah Akawu Denue² \\ 'Department of Histopathology, University of Maiduguri, Nigeria \\ ${ }^{2}$ Department of Medicine, University of Maiduguri, Nigeria
}

Correspondence: Ballah Akawu Denue, Department of Medicine, College of Medical Sciences, University of Maiduguri, Borno State, Nigeria, Email d_akawu@yahoo.co.uk

Received: February 08, 2018 | Published: April 25, 2018

Keywords: Mycosis fungoides, rare disease, histological diagnosis

\section{Introduction}

Mycosis fungoides (MF), also referred as granuloma fungoides was first described in 1806 by French dermatologist Jean-Louis-Marc Alibert. ${ }^{1}$ The name mycosis fungoides is a misnomer as it depict "mushroom-like fungal disease" due to its structural appearance. ${ }^{2}$ It is a form of cutaneous T-cell lymphoma that often involves the skin but can rarely shape up and affect the viscera. Based on WHO classification, the classical form of MF includes; folliculotropic, pagetoid reticuloid and granulomatous cuti laxa. ${ }^{3,4}$ The MF lesion is often due to uncontrolled peripheral T-cell epidermotropic lymphocyte cell division. ${ }^{3,5}$ It is estimated that about $65 \%$ of primary cutaneous lymphoma is the T-cell type, where as $25 \%$ are formed by B-cell and $10 \%$ are unspecified. ${ }^{5}$ The disease has an indolent clinical course but patients commonly present with a nodular skin rash, patches, and sometimes with associated skin itching. In the early stages, the skin patches can present as eczema or psoriasis-like lesion. ${ }^{2}$ Mycosis fungoides is a rare disease and its risk factors are not well elucidated worldwide. ${ }^{6}$ Due to lack of uniformity in MF presentation and dearth of facility and expertise for it detection, it is often under reported in developing nations. We therefore, report two cases that presented in unusual form to highlight the need to subject suspicious cutaneous lesion for histo-pathological studies.

\section{Case I}

A 20 year old female presented with a year history of a pair of painless swelling on the left cheek (Figure 1) (Figure 2). It was initially overlooked by the patient as an acne, but became worried when the swelling continue to increase in size and disfigure her face. The swellings were not associated with itching or discharge. There was no preceding history of trauma or relation to her monthly menstrual cycle. She had no other constitutional symptoms. On examination, the patient was clinically stable. She had two swellings on left cheek extending to the maxillary region measuring $8 \times 6 \mathrm{~cm}$ and $6 \times 4 \mathrm{~cm}$ respectively; it was diffuse, soft, nontender, no differential warmness and did not transilluminate.

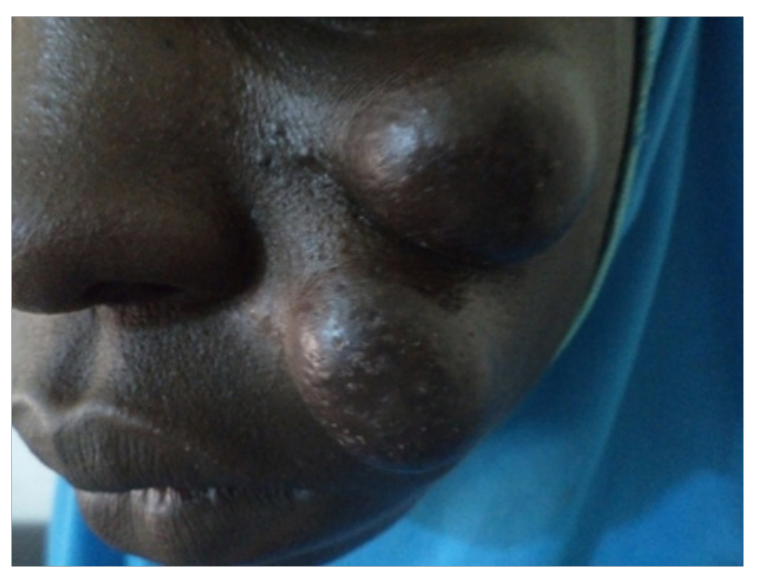

Figure I Left cheek swelling masquerading giant acne, side view.

Clinical diagnosis of neurofibromatosis was made and excision biopsy of the lesion was done after obtaining a written consent from the patient. Consent was also obtained before the pictures were trailed. 


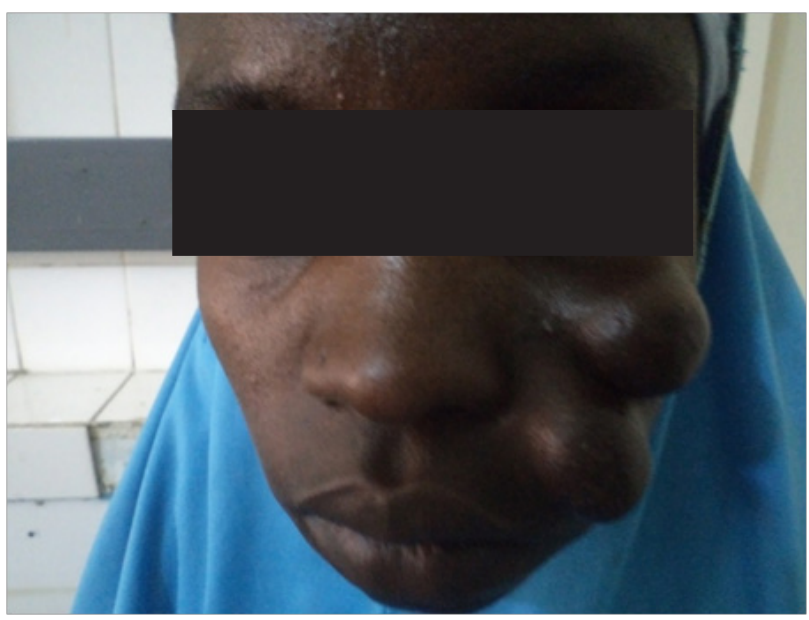

Figure 2 Front view.

\section{Morphology}

Gross specimen showed a rubbery grayish white tissue that was partly covered by an ellipse of skin and it measured $4.5 \times 2 \times 2 \mathrm{~cm}$. The cut surface appeared solid grayish white. Histological sections showed skin tissue displaying monomorphic lymphoid cells focally arranged in a nodular pattern invading the dermis with numerous foci of epidermal infiltrations (Figure 3) (Figure 4). The cells are predominantly small and medium sizes with an occasional blast and they have round to oval vesicular nuclei that have a cerebroid configuration. Focal pautriers microabscesses and areas of necrosis are present. The feature is consistent with Mycosis fungoides.

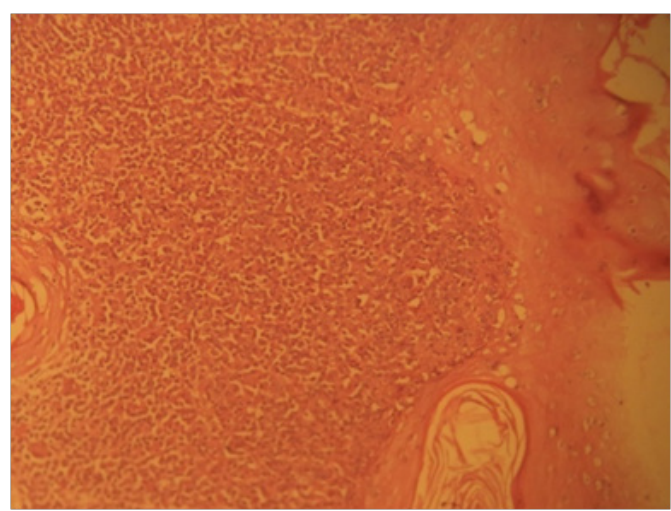

Figure 3 Photomicrograph shows monomorphic lymphoid cells infiltrating the dermis, akin to exocytosis, $\mathrm{H}$ and $\mathrm{E} \times \mathrm{I} 00$.

\section{Case 2}

A 60 year old female presented with 20 years history of patchy hypo and hyper pigmented skin lesions. The lesion was localized to the left arm (Figure 5); it was associated with mild itching. The lesion defies several medications including topical agents obtained over the counters and Hospitals. She presented due to distressing pruritus that had increased in intensity in the preceding two years. There was also cosmetic concern as the lesion was becoming disfiguring. On examination, there were multiple skin lesions predominantly hyperpigmented skin lesion with associated hypopigmentation. She was referred for further evaluation as a case of suspected aspergillosis. She had excisional biopsy at the left arm after obtaining her consent.

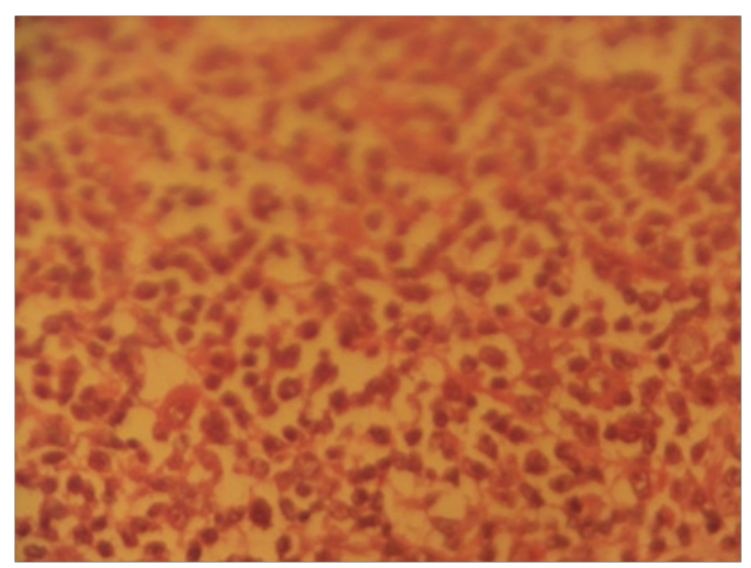

Figure 4 Photomicrograph shows diffuse monomorphic lymphoid cells with round to ovoid nuclei and moderate amphophilic cytoplasm. $\mathrm{H}$ and EXI00.

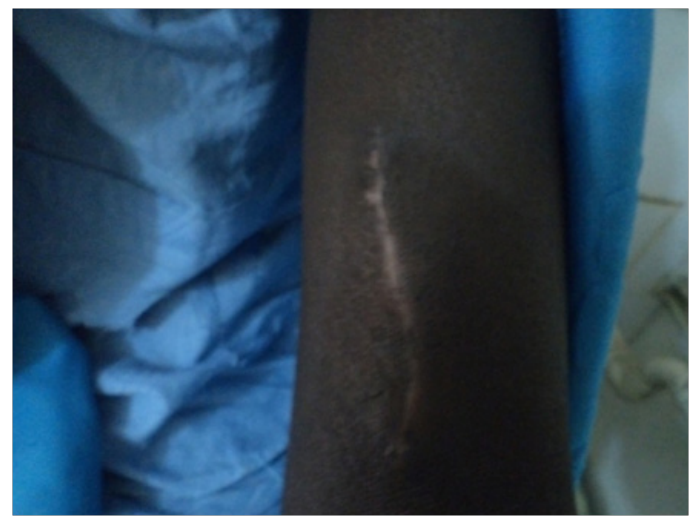

Figure 5 Excised left arm mass showing the healed scar.

\section{Morphology}

Gross examination showed fragments of gray, white tissue partly covered by skin aggregating $1.8 \mathrm{~cm}$. Histological sections showed ulcerated skin tissue exhibiting intradermal monomorphic lymphoid cells infiltrating the epidermis and the adipose tissue (Figure 6) (Figure 7).The cells have round to oval nuclei with the moderate amphophilic cytoplasm. Quite a few cells that have vesicular nuclei with the cerebroid nuclear pattern were noted. Focal areas showing pautriers microabscesses were also present and there is low mitotic activity (Figure 8). The overall features are consistent with Mycosis fungoides.

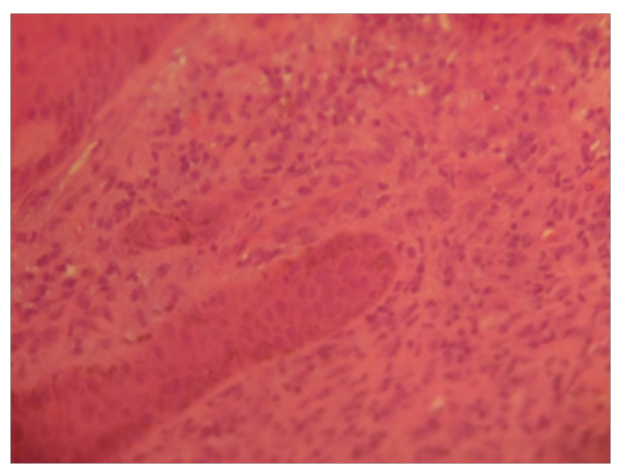

Figure 6 Photomicrograph shows monomorphic lymphoid cells exhibiting epidermotropism, $\mathrm{H}$, and EXI00. 


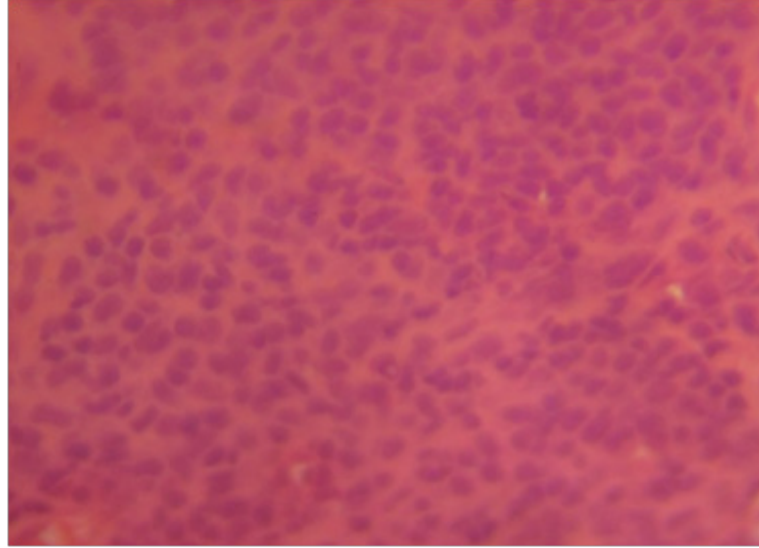

Figure 7 Photomicrograph shows diffuse monomorphic lymphoid cells with round to ovoid nuclei and moderate amphophilic cytoplasm. $\mathrm{H}$ and EXI00.

\section{Discussion}

Mycosis fungoides is a form of primary cutaneous non-Hodgkin lymphomas. In a myriad of dermatological lesions that may have similar morphology, high index of suspicion is necessary to establish a diagnosis of mycosis fungoides. ${ }^{7}$ Initial presentation may be in form of benign dermatomes' in form of patches, plaques, tumors or erthroderma, therefore definitive diagnosis can be delayed or missed. Clinical staging of mycosis fungoides is necessary for taking decision on treatment options and determining the prognosis. Various staging systems exists for mycosis fungoides, however two important classification; TNM staging system (Table 1) and Bunn and lamberts system (Table 2) that takes into consideration takes into consideration the extent of body surface area involved, lymph node status and erythroderma. ${ }^{8}$ The WHO and the European Organization for Research and Treatment of Cancer have also classified primary cutaneous lymphoma into; cutaneous T-cell lymphoma, cutaneous B-cell lymphoma, Cutaneous lymphoma from the natural killer cell and unclassified cutaneous lymphoma. These classifications were

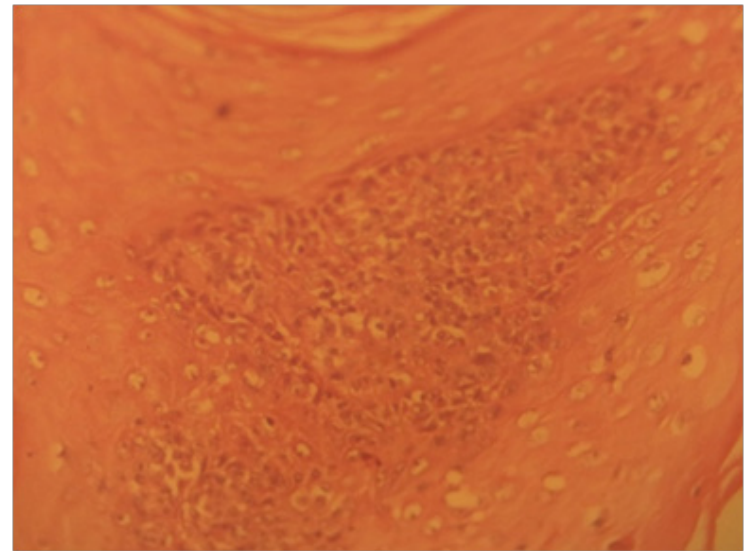

Figure 8 Photomicrograph shows the pautriers micro abscess, $\mathrm{H}$ and EXI00.

based on phenotype and molecular characterization. ${ }^{1,2,8}$ Mycosis fungoides expresses the T-cell receptor with $\alpha \beta+$ subunit and CD4+ immunophenotyping. ${ }^{2}$ The disease also represents $<1 \%$ of the total number of non-Hodgkin lymphoma, it has an indolent clinical course and better prognosis when detected early. ${ }^{1,5}$ An established association between MF and industrial exposure to oil has been observed. ${ }^{6}$ However, the risk factors of the disease are poorly understood. ${ }^{3-6}$ Primary cutaneous lymphomas are the second most frequent extranodal non-Hodgkin lymphoma in Europe an average incidence rate of 1/100,000 inhabitants have been observed, ${ }^{4-6}$ however, in our environment only two cases were experiential in four decades, perhaps the disease was under-diagnosed, looking at its wide clinical presentation that resembles two other skin lesions, as a result of this it is possible that many cases might have missed the definitive histological diagnosis. In the United State, from 1973 to 1992 the incidence of MF was $0.36 / 100,000$ inhabitant ${ }^{6,9}$ with the ratio between blacks to Caucasian put at 1.7:1. The proportion of the disease between Asians and the white was $0.6: 1 .^{10}$

Table I Stages of Mycosis Fungoides. TNMB Classification of Mycosis Fungoides and Sezary Syndrome

\begin{tabular}{ll}
\hline TNMB Classification of mycosis fungoides and sezary syndrome \\
T (skin) & Limited patch/plaque (involving< $10 \%$ of total skin surface) \\
TI & Generalized patch/plaque (involving $>10 \%$ of total skin surface) \\
T2 & Tumor(s) \\
T3 & Erythroderma \\
T4 & No enlarged lymph nodes \\
N (lymph node) & Enlarged lymph nodes, histologically uninvolved \\
N0 & Enlarged lymph nodes, histologically involved (nodal architecture unaffected) \\
NI & Enlarged lymph nodes, histologically involved (nodal architecture effaced) \\
N2 & \\
N3 & No visceral involvement \\
M (viscera) & Visceral involvement \\
M0 & \\
MI & No circulating atypical (Sezary) cells or <5\% of lymphocytes \\
B (blood) & Low blood tumor burden (>5\% of lymphocytes are Sezary cells, but not B2) \\
B0 & High blood tumor burden (I000/mL Sezary cells+positive clone) \\
BI & \\
B2 &
\end{tabular}


Table 2 Stages of Mycosis Fungoides. Bunn and Lambert system

\begin{tabular}{lll}
$\begin{array}{l}\text { Bunn and lambert } \\
\text { system }\end{array}$ & Clinical findings & $\begin{array}{l}\text { Tumor-node-metastass } \\
\text { stage }\end{array}$ \\
IA & $<10 \%$ BSA patch/plaque & TI No \\
IB & $>10 \%$ BSA patch/plaque & T2 No \\
IIA & $\begin{array}{l}\text { Patch or plaque with palpable nodes without histological } \\
\text { involvement }\end{array}$ & $\mathrm{TI} / 2 \mathrm{NI}$ \\
IIB & Cutaneous tumors with or without palpable nodes & T3 No/I \\
III & Erythroderma with or without palpable nodes & T4 N0/I \\
IVA & Non-palpably or palpable nodes with histological involvement & T-any N2/3 \\
IVB & Visceral involvement & T-any N-any MI \\
\hline
\end{tabular}

Table 3 Treatment of mycosis fungoides/Sezary syndrome

\begin{tabular}{|c|c|c|c|c|}
\hline Stage & First line & Second line & Experimental & Not suitable \\
\hline IA & Skin-directed therapy or no therapy & $\begin{array}{l}\text { Skin-directed therapy or no } \\
\text { therapy }\end{array}$ & Bexarotene gel & Chemotherapy \\
\hline IB & Skin-directed therapy & $\begin{array}{l}\text { a-Interferon+PUVA, Total skin } \\
\text { electron beam }\end{array}$ & $\begin{array}{l}\text { Denileukin Diftitox, } \\
\text { Bexarotene }\end{array}$ & Chemotherapy \\
\hline$\| A$ & Skin-directed therapy & $\begin{array}{l}\alpha \text {-Interferon+PUVA, Total skin } \\
\text { electron beam }\end{array}$ & $\begin{array}{l}\text { Denileukin Diftitox, } \\
\text { Bexarotene }\end{array}$ & Chemotherapy \\
\hline IIB & $\begin{array}{l}\text { Radiotherapy/total skin electron beam, } \\
\text { chemotherapy }\end{array}$ & $\begin{array}{l}\text { a-Interferon, Denileukin Diftitox, } \\
\text { Bexarotene }\end{array}$ & $\begin{array}{l}\text { Autologous PBSCT, } \\
\text { mini-allograft }\end{array}$ & Cyclosporin \\
\hline III & $\begin{array}{l}\text { PUVA }+\alpha \text { interferon, Extracorporeal photopheresis } \\
+\alpha \text { Interferon, methotrexate }\end{array}$ & $\begin{array}{l}\text { Total skin electron beam, } \\
\text { Bexarotene, Denileukin, Diftitox, } \\
\text { chemotherapy, Alemtuzumab }\end{array}$ & $\begin{array}{l}\text { Autologous PBSCT, } \\
\text { mini-allograft }\end{array}$ & Cyclosporin \\
\hline IVA & $\begin{array}{l}\text { Radiotherapy/Total skin electron beam, } \\
\text { chemotherapy }\end{array}$ & $\begin{array}{l}\text { a-Interferon, Denileukin Diftitox, } \\
\text { Alemtuzumab, Bexarotene }\end{array}$ & $\begin{array}{l}\text { Autologous PBSCT, } \\
\text { mini-allograft }\end{array}$ & Cyclosporin \\
\hline IV B & Radiotherapy, chemotherapy & Palliative therapy & Mini-allograft & - \\
\hline
\end{tabular}

In a survey in Switzerland, MF constitutes $60 \%$ of the total 263 primary cutaneous lymphomas (PCL) that were analyzed within nine year period and they establish a mean age of 59 years with a slight female preponderance in the proportion of $1: 1.4 .{ }^{11}$ In the present case study, the two patients were female, age 20 and 60 years respectively. Mycosis fungoides occurs as patch-like lesions with slight erythematous, pink or brownish coloration which can be a single or multiple lesion of different diameter. ${ }^{3-5,11}$ The lesion is often seen in covered areas usually gluteal region and thigh. ${ }^{11}$ In our case reports both patients presented with lesions in sun-exposed areas (cheek, limbs and upper back). Parapsoriasis, neurofibromatosis, aspergillosis and giant acne were differential diagnoses before the histology report in both patients. Sezery syndrome was ruled out based on a clinical basis, which shares similar histochemical markers with MF, even though MUM-1is always positive in Sezery and negative in MF. In our case reports the diagnosis was made based on morphological ground immune histo chemistry were not done because the tissue has lost its receptor integrity at the time of the request.

Study estimates that about $5 \%$ of MF occur in childhood and adolescence indicating that it is rare presentation. ${ }^{12}$ The progression of MF in such age group is supposed to be firmer and more aggressive with frequent extracutaneous involvement. ${ }^{11} \mathrm{MF}$ is characterized by epidermotropic peripheral T lymphocytes whose phenotype is CD2+, $\mathrm{CD} 3+, \mathrm{CD} 4+, \mathrm{CD} 5+, \mathrm{CD} 8-, \mathrm{CD} 45 \mathrm{RO}+, \mathrm{CD} 20$ +and CD30-, ${ }^{13}$ with few exceptional cases. Both Ki-67 and CD 30 are negative in the early stage of MF. Recent surveys have indicated that regular T-cell MF correlates well with the phase of the disease and prognosis particularly FOXP3 Tregs. ${ }^{11,14}$ Other diagnostic markers have been utilized to in hence early detection includes monoclonal T-cell lymphocytes, TCR gene rearrangement analysis using PCR. Knowledge about the molecular mechanism involved in the pathogenesis of the tumour progression in MF is poorly understood. In MF alteration of $\mathrm{p} 16 \mathrm{INK} 4 \mathrm{a}$ gene and p15INK4b gene were discovered in $7(18 \%)$ and $2(5 \%)$ out of 39 cases examined. ${ }^{15}$ Several treatment modalities for MF exist; topical therapy is the main stay of treatment for patch/ plaque type without extracutaneous involvement, whereas chemotherapy and other aggressive systemic regimens are reserved for recalcitrant disease or extracutaneous involvement. ${ }^{8}$ Various treatment modalities (Table 3) are available for treatment of mycosis fungoides and other cutaneous lymphoma that includes sunlight and ultraviolet light expose, steroid, topical and systemic chemotherapies, local superficial radiotherapy, 
histone deacetylase inhibitors vorinostat, total skin electron beam radiation, photopheresis and systemic therapist with interferon, retinoid, rexinoid or biological therapist. ${ }^{16}$ These treatments options has been tried in combination. The treatment modalities consider a tumour, node, metastasis, and blood staging system (TNMB) which also prognosticates a tumour. ${ }^{17}$ Both patients were counseled on their disease and $\mathrm{CHOP}$ cytotoxic treatment option. However both declined and were lost to follow up. The prognosis of patients with MF is highly dependent on the extent and type of skin involvement. Patients that present with plaque have a good prognosis with chance of survival similar to a matched control population. Conversely, patients with tomorous or erythrodermic type of skin lesion and extracutaneous disease have a poor prognosis. ${ }^{17}$

\section{Conclusion}

There is paucity of data on Mycosis fungoides in our environment even though it is common among the black race with male preponderance. The dearth of records of diagnosed cases in developing countries may be due to lack of facilities and expertise for histological evaluation. Other challenges include wide range of tropical infectious and non infectious skin lesions that masquerades as mycosis fungoides.

\section{Recommendation}

Detailed evaluation of skin lesion including histology is necessary in developing nations due to wide range of cutaneous lesions in the region.

\section{Acknowledgements}

None.

\section{Conflict of interest}

The author declares no conflict of interest.

\section{References}

1. Jawel SI, Myskowski PL, Horwitz S, et al. Primary T-cell lymphoma (mycosis fungoides and sězary syndrome): part II. Prognosis, management and future directions. J Am Acad Dermatol. 2014;70(2):e223.

2. Cerroni G, Lorenzo N, Kevin L, et al. An illustrated guide to Skin Lymphomas. Journal of Medicine. 2005;12(4):254-263.
3. Willemze R, Jaffe ES, Burg G, et al. WHO-EORTC classification for cutaneous lymphomas. Blood. 2005;105(10):3768-3785.

4. Swerdlow SH, Campo E, Harris NL, et al. WHO classification of tumors of haematopoietic and lymphoid tissues. Lyon: IARC; 2008.

5. Cerroni L, Gatter K, Kerl H, editors. Skin lymphoma the illustrated guide- mycosis fungoides. 3rd ed. UK: Wiley-Blackwell; 2009.

6. Morales Suarez VM, Llopis GA, Marquina VA, et al. Mycosis fungoides: a review of epidermiological observations. Dermatology 2000;201(1):21-28.

7. Sajjan V, Chandela M, Pandit AM, et al. Mycosis fungoides: The great imitator. Our Dermatol Online. 2015;6(1):76-79.

8. Horwitz SM, Olsen EA, Duvic M, et al. Review of the Treatment of Mycosis Fungoides and Sézary Syndrome: A Stage-Based Approach. $J$ Natl Compr Canc Netw. 2008;6(4):437-443.

9. Mori M. New Xenon-Chloride Lamp Useful for Treating Early-Stage Mycosis fungoides. Journal of American Academic Dermatology. 2004;50:943-945.

10. Prince H, Miles A, Whittaker MU, et al. How I treat mycosis fungoides and Sézary syndrome. Blood. 2009;114(20):4337-4353.

11. Yamashita T, Abbade LP, Marques ME, et al. Mycosis fungoides and Sezary syndrome: clinical, histopathological and immunohistochemical review and update. An Bras Dermatol. 2012;87(6):817-830.

12. Swerdlow A, Campo E, Harris NL, et al. WHO Classification of Tumours of Hematopoietic and Lymphoid Tissue. British Journal of Dermatology. 2008;13(1):188-197.

13. Ngo JT, Trotter MJ, Haber RM. Juvenile-onset mycosis fungoides mimicking vitiligo. J Cuten Med Surg. 2009;13(4):230-233.

14. Fried L, Cerroni L. FPXP3 in sequential biopsies of progressive Mycosis fungoides. AM J Dermatopathol. 2012;34(3):263-265.

15. Vakeva L, Pukkala E, Ranki A. Increased risk of secondary cancers in patients with primary cutaneous $\mathrm{T}$ cell lymphoma. $J$ Invest Dermatol. 2000;115(1):62-65.

16. Sander CA, Flaig MJ, Jaffe ES. Cutaneous manifestations of lymphoma, a clinical guide based on the WHO classification. Clin Lymphoma. 2001;2(2):86-100.

17. Carroni L. Mycosis fungoides. 2017. 